\title{
Petrochemical Steel Pipe Rack: Critical Assessment of Existing Design Code Provisions and a Case Study
}

\author{
Luigi Di Sarno $^{1,2}$ (]) $\cdot$ George Karagiannakis ${ }^{1}$
}

Received: 28 January 2019 / Accepted: 13 September 2019 / Published online: 20 September 2019

(c) The Author(s) 2019

\begin{abstract}
The investigation of the seismic integrity of petrochemical plant steel structures should be commensurable to their importance given the high necessity for human life safety and financial robustness. To date, it is demonstrated in the existing literature that still many grey areas of knowledge exist upon the appropriate application of code provisions on non-building structures design. Indeed, the selection of seismic design parameters such as system performance factors or important classes are still vague aspects, in contrast with those for common building structures, either because of the paucity of information of seismic codes or due to the structural peculiarities that characterise the industrial structures resulting in the difficulty of defining 'all-encompassing' design parameters. The present paper aims at highlighting those parameters considering also a case-study that pertains to a steel pipe rack. The pipe rack is designed and analysed in the linear and nonlinear regime, both statically and dynamically, according to the Italian and European codes. American code provisions are examined as well so as possible inconsistencies might be found. It is demonstrated that the common nonlinear static analysis (pushover analysis) cannot be used to assess the response of the rack and the behaviour factor selection from current standards could be unjustifiable. Also, common engineering demand parameters, e.g. interstorey drift ratio, need further assessment vis-à-vis the response of nonstructural components of which the current design method does not comply with modern methods.
\end{abstract}

Keywords Steel pipe rack $\cdot$ Seismic code provisions $\cdot$ Modelling $\cdot$ Seismic design $\cdot$ Importance factors $\cdot$ Behaviour factors

\section{Introduction}

The cruciality of non-buildings structures that constitute the petrochemical/oil refineries is significantly higher than that of common ones given the repercussions that a failure of nonstructural components may cause to the nearby units and community afterwards. The accidents in chemical plants are numerous and occur frequently, exposing human lives and environment at risk. There are two significant examples in Europe, namely the 2017 and 2018 fire explosions at Sannazzaro oil refinery in North Italy and Vohburg refinery in southeastern Germany that caused human injuries, extensive damage to the plants and forced local authorities to consider evacuations of the nearby communities due to the toxic substances dispersed in the atmosphere. Furthermore, the
Luigi Di Sarno
ldisarno@unisannio.it
University of Sannio, Benevento, Italy
2 University of Liverpool, Liverpool, UK

seismic integrity of these type of plants was, is and will be a top priority issue on the agenda of societies due to their intrinsic relationship with the economic resilience of communities on regional and/or supra-regional level. Natural Technological (NaTech) events of the past have shown that non-building structures -similar and non-similar to buildings-, and components supported on them, are vulnerable against earthquakes (Krausmann et al. 2010, 2011; Sezen et al. 2006; Suzuki 2008). When it comes to non-building structures similar to buildings e.g. pipe racks, it seems that they are not the most vulnerable structure themselves, however, they could be when being connected with piping systems. This is what the research of Kidam and Hurme (2013) yielded; the inquiry of 364 chemical process industry accidents showed that piping system failures-as piping system defined any type of connection between pipework and process units-was the most frequent out of 12 apparatuses in total. Also, failures that referred to the layout and fabrication of the piping and supporting structure system comprised the second and third highest percentage after human and organizational errors. 
Pipe racks (or supporting structures) comprise primarily steel structures in Petrochemical Plants (PPs) and support pipes that transfer hazardous materials from one unit to another. The high demand for constructing industrial steel structures with seismic safety is evident, taking into consideration that several oil refineries are located in high seismic-prone countries e.g. Italy, Greece, Turkey, USA, Canada, China, Taiwan, Japan and many others. Seismic design requirements such as the behaviour factor (q-factor) or the importance factor ( $\gamma$-factor) and analysis methodologies should be well-determined. Although the evaluation of the aforementioned factors seems to be a mature issue, nowadays, for common building structures, the situation is not the same for the structures under consideration. At least to the Authors' knowledge, there are very few research efforts that undertake the seismic design of petrochemical steel pipe racks (Bedair 2015; Di Roseto et al. 2017; Drake and Walter 2010) and even these publications not in a comprehensive manner since parameters e.g. behaviour factor selection or nonbuilding structure-nonstructural components interaction are not dealt with sufficiently.

When it comes to codes, the main European (EN) contribution for seismic design issues (EN1998-1 2004) does not make reference to seismic design requirements of industrial structures, postulating q-factors only for steel structures (regular and irregular), which differentiate in many ways compared to the petrochemical pipe racks. Also, additional European standards such as EN13480-3 (2012), EN1998-6 (2005) and FEM10.2.08 (2011) refer either to different petrochemical plant structures or to different type of racks (e.g. storage pallet racks) that are not comparable with the pipe racks, due to the different type of loading and operational purposes. On the contrary, American (AM) codes e.g. ANSI-RMI (2008), ASCE/SEI 7-16 (2017) and FEMA P-751 (2012) stipulate seismic design criteria and parameters for steel pipe racks in particular, as it is illustrated in the ensuing section, such as values for the response modification factor (also termed R-factor), or analysis methodologies. However, the adoption of q-factor (a.k.a. structural response quality factor) proposed by the codes can be characterized as unsafe and unjustifiable if we consider the various structural formulations and peculiarities of PP steel pipe racks. It is important what analysis method will be adopted for the assessment of the pipe rack. For example, the nonlinear static analysis, namely the conventional Pushover Analysis (PA), may be erroneous if higher modes or high torsional effects exist; thus an alternative method, such as, for example, time-history or multi-modal PA could be more appropriate (Elnashai and Di Sarno 2015).

Furthermore, a key parameter when designing and assessing a pipe rack-piping system that increases considerably the risk due to possible uncertainties included in refers to the dynamic interaction and type of pipe supports. The EN codes do not deal with this matter at all, whereas the AM ones propose some empirical rules in terms of mass and period, which are discussed in the following. Although, the matter is rather crucial for the safe design of industrial facilities, the research is rather limited. For example, a number of parametric analyses on a piping system and its supporting structure was conducted in Azizpour and Hosseini (2009) by considering different configurations such as the number of supported pipes or different diameter of pipes, end conditions and diameter of link connections (U rings). The authors concluded that the frequency of the system can significantly be affected by the type of link elements (diameter of links).

The seismic design process of pipe racks that should be followed by practicing and professional engineers requires coordination of different disciplines as illustrated above. Another key aspect that is being investigated by the Authors refers to soil effects since midstream and downstream facilities are placed at coastal sites where could be loose and liquefiable. The attempt for dealing with these challenging tasks comes against the design codes insufficiency that causes engineers to overlook critical design aspects and design pipe racks in an uneconomical way towards avoiding the complexity and meeting the time constraints.

The present paper aims at shedding light on design parameters that characterize the type of structure in-hand in the way of making the seismic design more justifiable. Before the assessment of behaviour factor and estimation of Interstorey Drift Ratio (IDR) values of a steel pipe rack, seismic response spectrum parameters such as Recurrence Period (RP), Limit States (LSs), q-factors, $\boldsymbol{\gamma}$-factors and soil classification as proposed by EN (including Italian) and AM codes will be compared so as possible dissimilarities to be found. The work presented herein does not aim at covering every aspect involved in the seismic design process of petrochemical pipe racks yet to form the starting point for further research and recommendations.

\section{Behaviour Factors for Steel Pipe Racks}

Earthquake loads that structures can experience during a seismic event are much more than what they are designed for. In contrast with primary loads e.g. wind loads (high frequency scenario), seismic forces may overcome more than half the weight of a structure in the horizontal direction. To avoid the construction of heavy structures with high costs, the concept of damage limitation and collapse-prevention can be introduced, thus it is known a priori that they are going to experience damage during a middle-to-severe earthquake event. Consequently, it is up to the structural engineer to decide the type, location and extent of damage based upon the risk that a structure exhibits to human life and environment (Elnashai and Di Sarno 2015); this is also 
called dissipative design approach. The latter fundamental concept of seismic design is achieved by introducing a reduction factor. The seismic codes propose the so-called 'inelastic spectrum analysis'; in fact, the analysis is elastic, it is called inelastic, though, due to the inelastic response that a structure is expected to experience during a severe earthquake. This type of analysis is considered as practical and is adopted by the seismic codes (EN1998-1 2004; ASCE/ SEI 7-16 2017; FEMA P-751 2012; IBC 2015). The global inelastic response, in contrast with the local response, has always relied on the reduction factor, whereas the method of assessing the local response has changed in many engineering structures by introducing the Limit States Design (LSD).

Depending on the type of steel structures, which are mainly categorized as ordinary, intermediate or special frames, the energy dissipation capacity is defined as low, moderate and high, respectively. The energy that a structure is able to dissipate during an earthquake is related to its capacity to deform in the inelastic regime. The ductility demand for steel pipe racks is not high considering that other non-building structures or pipework is supported either rigidly or flexibly on it and thus high deformation may cause early failure and hazardous material leakage, afterwards, to the most critical components. The value of q-factor varies among the different types of steel structures, namely concentrically Braced Frames (BFs) with eccentric or concentric bracing, Moment Resisting Frames (MRFs) or dual systems due to the various performance levels to be achieved, the detailing of connections, the number of stories, the soil conditions or the seismic design method considered. Several attempts have been made to assess the value of behaviour factor of common steel structures (Asgarian and Shokrgozar 2009; Asgarian et al. 2010; Elghazouli 2009; Izadinia et al. 2012; Miranda and Bertero 1994). Through these investigations many aspects upon the correct estimation of structural response quality factor have been clarified such as the limitation of the traditional pushover analysis to account for higher mode effects and member stiffness changes (Izadinia et al. 2012). As it is demonstrated in the following case-study, the higher mode contribution could be substantial when nonbuilding structures are under examination. There are two tendencies of force reduction factor adopted by researches in the literature for seismic design, namely the EN and AM, which are addressed in the following sections.

\subsection{European Codes}

The behaviour factor is defined as the ratio of the strength demand if the structure were to respond elastically under the design earthquake to the inelastic strength demand, where the structure behaves beyond the elastic range but within the specified ductility limits. More specifically, if the elastic strength demand is defined as $\mathrm{F}_{\mathrm{e}}$ and the inelastic strength one as $\mathrm{F}_{\mathrm{d}}$, it follows that:

$q=F_{e} / F_{d}$

According to (Elnashai and Di Sarno 2015), the value of q pertains to the ductility of the structure (the ductility is strongly related with the detailing of structural members), the overstrength of individual members (the redundancy plays an important role in the strength that a structure reserves) and the damping of the structure-the last is not in a straightforward relationship with the q-factors, thus most of the time it is omitted. The way in which the behaviour factor is defined in EN varies primarily as a function of the material of construction and the lateral resisting system utilized; thus, different q-factors are provided, for instance, for reinforced concrete and steel frames. The difference lies mainly in the overstrength ratio $a_{u} / a_{1}$, which is given in the following equation:

$q=q_{o} \cdot a_{u} / a_{1}$

where $\mathrm{q}_{\mathrm{o}}$ is the basic value of behaviour factor; $a_{1}$ is the value by which the horizontal seismic action is multiplied in order for any member to reach its flexural resistance and $\mathrm{a}_{\mathrm{u}}$ is the value by which the horizontal seismic design action is multiplied in order for plastic hinges to be formed able to cause an overall structural instability. The ratio $\mathrm{a}_{\mathrm{u}} / \mathrm{a}_{1}$ can be obtained either by analysis calculations or by default values proposed by the (EN1998-1 2004) for different steel frame systems. The values of q-factors that the last code determines for steel frame systems with Medium or High Ductility Class (DCM and DCH) and irregular in elevation are shown in the Table 1.

The values shown in the table above come after a reduction by $20 \%$ of the relevant values for regular structures as the code specifies. The values have decreased deliberately so as the comparison with the values proposed in the following by the AM code to be feasible, making the assumption that petrochemical steel pipe racks are usually irregular along the height. The overstrength ratio $\mathrm{a}_{\mathrm{u}} / \mathrm{a}_{1}$ is introduced for DCH. The value of overstrength ratio varies between 1.1 and 1.3 for MRF and is equal to 1.1 for CBF. Greater values of the

Table 1 Behaviour factors (q) for irregular steel structures (EN1998-1 2004)

\begin{tabular}{lll}
\hline Structural type & DCM & DCH \\
\hline MRF & 3.20 & $4.00 \mathrm{a}_{\mathrm{u}} / \mathrm{a}_{1}$ \\
CBF & & \\
$\quad$ Digonal & 3.20 & 3.20 \\
V-bracing & 1.60 & 2.00 \\
EBF & 3.20 & $4.00 \mathrm{a}_{\mathrm{u}} / \mathrm{a}_{1}$ \\
Dual & 3.20 & $3.20 \mathrm{a}_{\mathrm{u}} / \mathrm{a}_{1}$ \\
\hline
\end{tabular}


overstrength ratio can be adopted in case nonlinear pushover analysis is used, however, the value cannot be higher than 1.6.

The results of analytical calculations upon the behaviour factor estimation have proved that the value of q-factor proposed by the EN is quite smaller than the product of ductility and overstrength reduction factor. Structures have to withstand seismic forces that correspond to higher seismic intensity than that of 475 years return period, and this is why the codes propose conservatively lower values of the factor in order to keep structures safe enough. However, when it comes to structures of higher importance e.g. oil refinery pipe racks, the values prescribed by the codes could be non-risk related and thus unjustifiable. Recently, a new risk-targeted design method has been introduced (Celano et al. 2018; Dolšek et al. 2017a, b) that accounts for different limit states in order to take the seismic risk in a more justifiable way into account. The method introduces a risktargeted safety factor $\left(\gamma_{\text {im }}\right)$, which is equal to the ratio of seismic intensity corresponding to a designated return period (e.g. $\mathrm{T}_{\mathrm{LR}}=713 \mathrm{yrs}$ in the following case-study) and the mean value of seismic intensity that causes collapse; although, the first value can be found in seismic hazard maps, the second one is calculated numerically from the risk-equation by considering the hazard curve $\mathrm{H}\left(\mathrm{S}_{\mathrm{a}}\right)$ at a site and the target risk $\mathrm{P}_{\mathrm{c}}$. Finally, the risk-targeted behaviour factor is given by:

$q=r_{s} \cdot r_{\mu} \cdot C_{p}$

where $r_{s}$ is the overstrength factor, $r_{\mu}$ is the ductility factor and $\mathrm{C}_{\mathrm{p}}$ pertains to the correction factor due to the risktargeted definition being equal to the inverse of safety factor $\left(\gamma_{\mathrm{im}}\right)$. The Eq. 3 has been included in the new generation of EN codes.

\subsection{American Codes}

The response modification factor $(\mathrm{R})$ - it is recognized that this term offers a better indication of the role that this factor represents-is defined in the American codes in a similar way:

$R=R_{\mu} \cdot \Omega$

The factor $\mathrm{R}_{\mu}$ corresponds to the ductility factor, whereas the factor $\Omega$ to the overstrength. As mentioned above, attention should be given when the AM codes are followed during the design process considering that the values of R-factor proposed refer to the highest possible recurrence period of earthquake, which is 2475 years (probability of occurrence $2 \%$ in 50 years), whereas the multinational EN codes or the national Italian code (NTC 2008) consider return period equal to 475 years (probability of occurrence $10 \%$ in 50 years).
Table 2 Response modification factors (R) for steel pipe racks (ASCE/SEI 7-16 2017)

\begin{tabular}{llll}
\hline Structural type & Ordinary & Intermediate & Special \\
\hline MRF & 2.33 & 3.00 & 5.33 \\
CBF & 2.17 & - & 4.00 \\
\hline
\end{tabular}

Table 3 Reliability factors as specified in the three codes

\begin{tabular}{llll}
\hline IC/RC & EN & NTC & AM \\
& $\gamma_{\mathrm{I}}\left(\mathrm{ag}=\gamma_{\mathrm{I}} \cdot \mathrm{a}_{\mathrm{gR}}\right)$ & $\mathrm{C}_{\mathrm{U}}\left(\mathrm{V}_{\mathrm{R}}^{*}=\mathrm{C}_{\mathrm{U}} \cdot \mathrm{V}_{\mathrm{N}}^{*}\right)$ & $\mathrm{I}_{\mathrm{e}}$ \\
\hline I & 0.80 & 0.70 & 1.00 \\
II & 1.00 & 1.00 & 1.00 \\
III & 1.20 & 1.50 & 1.25 \\
IV & 1.40 & 2.00 & 1.50 \\
\hline
\end{tabular}

$* V_{N}$ and $V_{R}$ are the nominal and reference life of a structure

In Table 2, values of R-factors for three different ductility classes and two structural types of steel pipe racks are illustrated. The values have been converted to refer to earthquake event with the same occurrence as per EN codes; in doing so, the comparison between them is made feasible. The values of reduction factors are comparable being greater or lower in one code compared to the other. The AM code does not specify values of R-factor for intermediate ductility CBFs. Also, it is worth mentioning that, in contrast with the EN code, the AM one proposes R-factor for ordinary pipe racks; this is reasonable considering the low ductility demand for this type of structure. The R-factor values shown in Table 2 do not consider increase of pipe rack height, since it is not considered in EN1998-1 (2004), however, they do account for the overstrength factor included in the pertinent table of AM code, which is equal to 3 and 2 for MRF and $\mathrm{CBF}$, respectively.

\section{Importance Classes}

Based on the consequence of failure e.g. risk to human life or economic repercussions, civil engineering structures are designed to meet specific reliability requirements. Reliability differentiation is attained by introducing an importance factor $\gamma_{\mathrm{I}}$ for each importance class (or usage class) into which every structure is classified. The EN code (EN1998-1 2004) defines four importance classes for buildings and recommends the value of $\gamma_{\mathrm{I}}$ to vary from 0.8 to 1.4 (Table 3 ), however, considering that the value of the factor should be determined according to the national seismic zones but the ramifications of a failure, the code proposes the values of National Annexes to be accounted for. The value of importance factor can be estimated as follows $(\mathrm{EN})$ : 
$\gamma_{I}=\left(\frac{T_{L R}}{T_{L}}\right)^{-1 / k}=\left(\frac{P_{L}}{P_{L R}}\right)^{-1 / k}$

where $T_{L R}$ is the recurrence period of the reference seismic action with probability of exceedance $\mathrm{P}_{\mathrm{LR}} ; \mathrm{T}_{\mathrm{L}}$ is the target recurrence period with the same probability of exceedance $\mathrm{P}_{\mathrm{LR}} ; \mathrm{P}_{\mathrm{LR}}$ is the probability of exceedance of the reference seismic action in $\mathrm{T}_{\mathrm{L}}$ years; $\mathrm{P}_{\mathrm{L}}$ is the probability of exceedance over the same $T_{L}$ years and $k$ is a factor equal to 3 . Although EN accounts for the reliability of structures by multiplying the reference Peak Ground Acceleration (PGA) $\mathrm{a}_{\mathrm{gR}}$ by $\gamma_{\mathrm{I}}$, the Italian code directly takes the importance of a structure into account by increasing the recurrence period of the seismic input by $\mathrm{C}_{\mathrm{U}}$, which varies from 0.7 to 2 in NTC (2018) (Table 3).

The American code ASCE/SEI 7-16 (2017) except for defining four Risk Categories (RCs) for buildings and other structures, which are represented by the importance factor $\mathrm{I}_{\mathrm{e}}$ (Table 3), it also introduces the Seismic Design Categories (SDCs), correlating the seismicity of the site with the reliability class, and the nonstructural component importance factor $\mathrm{I}_{\mathrm{p}}$. When a more comprehensive classification of structures into SDCs is considered essential, the code makes reference to authority having jurisdiction to adjudicate based upon a hazard assessment of an overall management plan, e.g. in the case of petrochemical plants, the authority may be the Ministry of Energy and/or Environment. Furthermore, structural and nonstructural components that are subjected to earthquake shall be designed based upon the target reliability in which the RCs are correlated with the conditional probability of failure for overall structural stability and individual seismic integrity of ordinary structural members. Such a kind of assignment of probability of failure to each importance class is not explicitly determined in the NTC or EC8, where the limit states (only the probability of exceedance of seismic input is considered probabilistically), as it will be discussed afterwards, are defined in such a way. Additionally, structures are assigned to SDCs through the 1 -s acceleration $S_{D 1}$ and short-period acceleration $S_{D}$. The SDCs are used as a conditional parameter for determining the allowable height, the drift limits, the analysis procedure and other seismic design requirements of structures under the design earthquake ground motion.

\section{Comparison of Acceleration Response Spectra}

In the following, the response spectra as specified by each code of reference are compared for Usage Class (UC) III, Safe Life Limit State (SLLS) and different Soil Types (STs). To make the comparison of response spectra consistent, the following assumptions are made: a) site coefficients such as the $\mathrm{F}_{\mathrm{o}}$ (maximum soil amplification factor as per NTC), $\mathrm{T}_{\mathrm{C}}^{*}$ (reference value for the determination of the initial period of velocity-controlled spectrum segment) and Zero Period Acceleration (ZPA or $\mathrm{S}_{\mathrm{e}(\mathrm{T}=0)}$ ) considered in NTC will be estimated according to the site that the pipe rack of the following case-study is placed (coastal zone of Milazzo, Sicily), b) the short- and long-period accelerations $S_{s}$ and $S_{1}$ specified in AM code have been adopted in that way so as the ZPA to be the same for each code spectrum of each soil type, the maximum spectral acceleration to be the same with the NTC for the first soil type and the $S_{D 1}$ to be greater than the ZPA and c) all the spectra have been formed for spectral period less than $4 \mathrm{~s}$ since this is the maximum value considered in EN.

As shown in Fig. 1, the ST2 of EC8 has a small plateau of constant $\mathrm{S}_{\mathrm{e}}\left(\mathrm{T}_{\mathrm{C}}<0.5\right.$, where $\mathrm{Tc}$ is the time period at which the descending segment starts), whereas the ST1 of EC8 and the NTC have almost the same period range with constant
Fig. 1 Comparison of response spectra for UCIII, SLLS and all STs
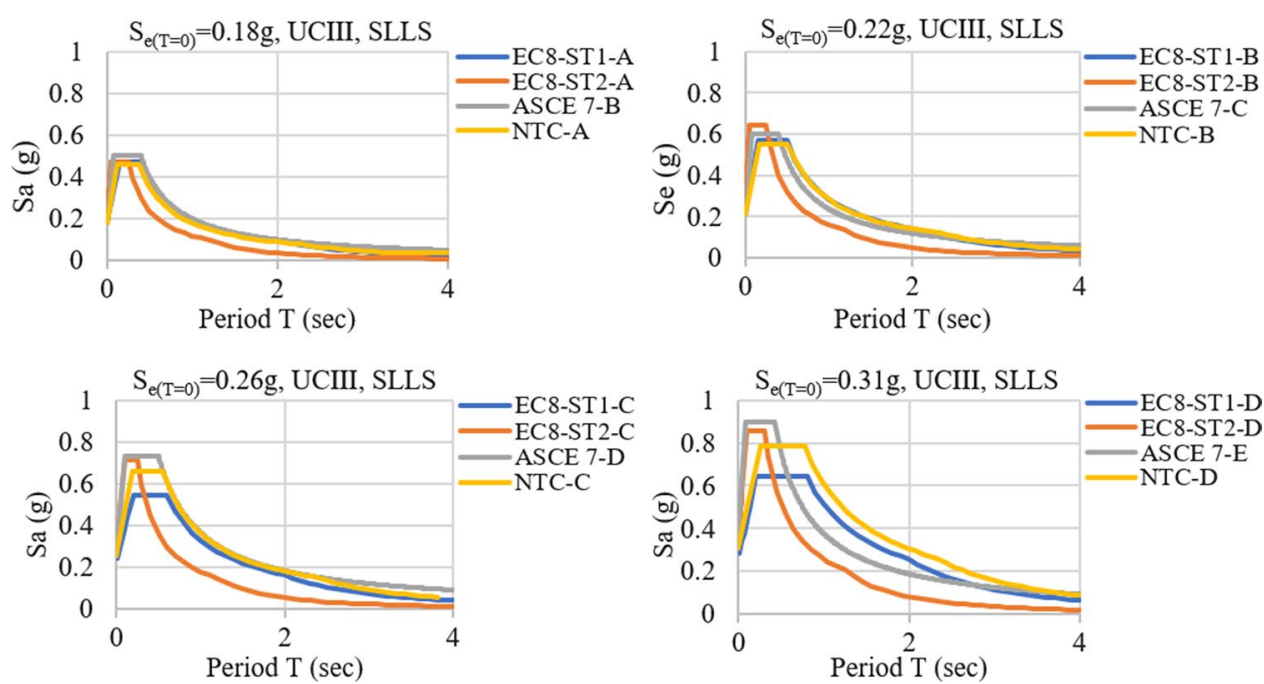
plateau. The ASCE 7 presents a different tendency almost for each soil type having either $S_{e}$ smaller of other spectra or the same compared to the NTC for $\mathrm{T}>\mathrm{T}_{\mathrm{C}}$. The maximum $\mathrm{S}_{\mathrm{e}}$ differentiates among the RSs except for STA due to the different soil factor $\mathrm{S}$ proposed by the codes. For instance, the NTC and ASCE 7 determine the soil amplification factor taking the usage class and the target reliability of structures into account. The ST2 of EC8 seems to have the greatest $\mathrm{S}_{\mathrm{e}}$ for $\mathrm{T}<\mathrm{T}_{\mathrm{B}}$ (time period at which the plateau starts), whereas the NTC has the highest $S_{e}$ for period $T>T_{C}$. For the majority of STs, the ASCE 7 postulates the highest $\mathrm{S}_{\mathrm{e}}$ for essential facilities (UCIII). This is because of the greater value of importance factor $\mathrm{I}_{\mathrm{e}}$ compared with the rest of codes (this is not the case for ordinary buildings, UCII, where either the NTC or ST2 of EC8 propose the maximum $\mathrm{S}_{\mathrm{e}}$ ). The NTC has greater or equal spectral acceleration values with the ST1 of EC8 yet mildly less than those of ST2 and propose less maximum $\mathrm{S}_{\mathrm{e}}$ for STE compared to STD (the ST2 of EC8 behaves in the same manner).

\section{Case-Study}

The present case-study pertains to the design, analysis and assessment of a three-floor petrochemical plant steel pipe rack (Fig. 2a). The rack is $12 \mathrm{~m}$ high ( $4 \mathrm{~m}$ each floor) and is outfitted with a piping system, which runs along the length and the height of the third floor. The pipe rack consists of different HEB and IPE section profiles as well as circular or rectangular concentric bracing (X-crossing or inverted $\mathrm{V}$ ) in vertical and horizontal direction. Elastoplastic material of steel grade S275 with strain hardening is considered. The piping system constitute 8" and 6" (Nominal Pipe Size, NPS) pipes with nominal yield and ultimate material strength 418 and $554 \mathrm{MPa}$, respectively and two horizontal vessels of $2 \mathrm{~cm}$ thickness. It is assumed that the piping system transfer a hazardous but not toxic material (Directive 67/548/EEC 2004), namely propylene, with unit weight $\gamma=5.42 \mathrm{kN} / \mathrm{m}^{3}$ (Karamanos et al. 2006) at zero internal pressure in order to stay on the safe side [more information can be found in Bursi et al. (2015)]. To account for the liquid, the density of pipes and tank material has increased (the increase fluctuate between 36 and $62 \%$ for the pipes and is equal to $170 \%$ for the tanks).

It is worth mentioning that the piping system includes nine (9) elbows, one T-joint and two nozzles; it is common in oil refinery industry, horizontal expansion loops of pipes to be formed in order to minimize the internal pressure and this is the reason that pipes run out of the main frame of the rack (Bedair 2015). Also, it is a common industry practice, the location of pipe supports e.g. anchors to be clearly shown on isometric drawings and provided to structural engineers prior to pipe rack layout configuration, thus, more information on the geometry and the configuration of the pipe rack and piping system can be found in Bursi et al. (2016). Finally, engineers adopt a uniform load on pipe rack beams (bents and/or struts) to account for small pipes and future installation, which practice has been adopted herein by considering $4.5 \mathrm{kN} / \mathrm{m}$ (it refers 1.5 times the maximum concentrated load on the rack by the existing piping system).

\subsection{Modelling and Design of the Pipe Rack-Piping System}

A piping system can be modelled by using beam elements as specified in EN13480-3 (2012) and ASME B31.3 (2008). A critical issue that arises when using beam elements for the modelling of pipes pertains to the nonlinear geometry of pipe bend. To take the higher flexibility of those critical components into account, the thickness of the straight beam that substitutes the curved pipe decreases according to a rough code-related rule as specified in EN13480-3

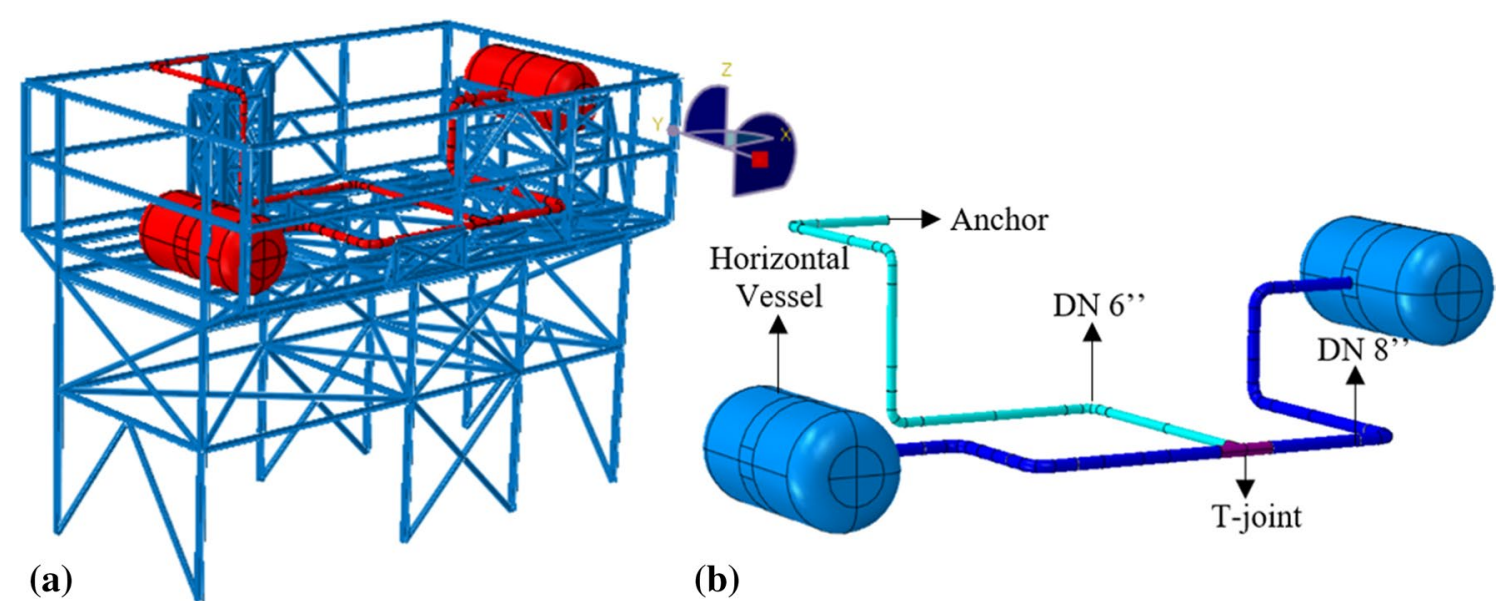

Fig. 2 a The three-floor steel rack and $\mathbf{b}$ the piping system configuration 
(2012) and Bursi et al. (2016). Another way of modelling the pipe bent that has been adopted and assessed herein by using beam elements is proposed by Bursi et al. (2015). The method attempts to form an 'Equivalent Straight Elbow, ESE' (straight beam) that has the same flexibility with the original one by using the Euler-Bernoulli theory. In particular, the stiffness of the original elbow (see Fig. 3a for the modelling of elbow on ABAQUS) is set equal to the one of a straight beam by subjecting the elbow into axial, shear and bending loading. In fact, the only parameter that changes in the end is the pipe thickness of the straight element. The reader who is interested in this methodology can find more info in Bursi et al. (2015). It is emphasized that beam elements proposed by the codes are not accurate and definitely inappropriate to capture the nonlinear deformation of the pipe (the so-called ovalisation phenomenon), however, neither EN nor AM codes deal with shell elements.

The use of beam elements instead of shell ones should be treated with care given that the former type of elements may be incapable of estimating all the fundamental frequencies of the pipeline, which can be found, though, by shell elements or experimental tests. A modal analysis has been conducted on ABAQUS software (ABAQUS 2017) for the pipeline shown in Fig. $2 b$ by using shell elements. As it is illustrated in the first row of Table 4, the beam elements that have been examined in Bursi et al. (2015) lose the first fundamental frequency of the pipeline, whereas the results from the experimental (DeGrassi et al. 2008) and ABAQUS analyses seem quite similar. Further assessment of shell and beam elements response has been done by exciting the piping system with a suite of 7 time-histories on ABAQUS software. The outcomes of such assessment prove that beam elements cannot capture all the peak values of stress-strain response (one out of 7 time-histories is shown in Fig. 3b), constituting the accuracy of beam elements questionable, and thus the response of pipes will be examined exclusively with shell elements hereafter.

Furthermore, modelling issues that pertain to the interaction of piping system on the pipe rack are crucial for these types of structures and could change significantly the global seismic response. The European codes do not treat the problem of non-building structure-nonstructural component interaction, whereas the American code ASCE/SEI 7-16 (2017) or the guideline ASCE (2011) (the latter makes reference specifically to petrochemical plants) specify a rough rule based upon the rigidity of connection and the weight of each system. If the non-building structure not similar to building and nonstructural components weight $\mathrm{W}_{\mathrm{p}}$ is less than $25 \%$ of the weight of the entire system $\mathrm{W}_{t}$, then the interaction could be neglected, and each structure could be designed and analysed separately. On the contrary, if the supported system weighs more than $25 \%$, then, the coupled system should be considered either by considering the nonbuilding structure only as a rigid element with appropriate distribution of each seismic weight (rigid response with $\mathrm{T}<0.06 \mathrm{~s}$ ) or modelling the whole system in the same

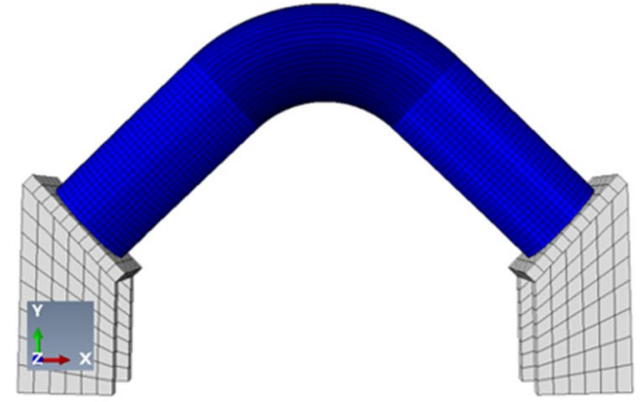

(a)

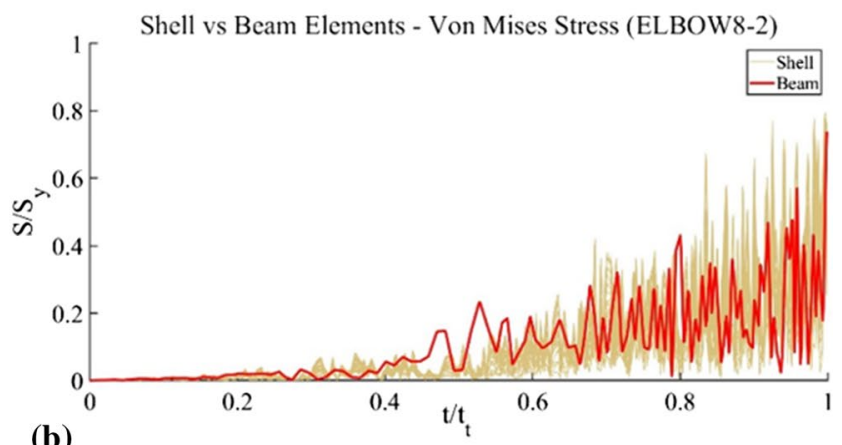

(b)

Fig. 3 a The numerical model of elbow on ABAQUS for the ESE formulation, and $\mathbf{b}$ the comparison of stress time-history by using beam and shell element at an elbow on the piping system ( $\mathrm{t}_{\mathrm{t}}$ : total record time, $\mathrm{S}_{\mathrm{y}}$ pipe yielding stress)

Table 4 Evaluation of frequency (in Hertz) of the piping system

\begin{tabular}{lllll}
\hline $\begin{array}{l}\text { Beam elements } \\
(1)\end{array}$ & $\begin{array}{l}\text { Experimental tests } \\
(2)\end{array}$ & $\begin{array}{l}\text { Shell elements } \\
(3)\end{array}$ & $\begin{array}{l}\text { Variation } \\
(1) \text { versus (3) }\end{array}$ & $\begin{array}{l}\text { Variation } \\
(2) \text { versus (3) }\end{array}$ \\
\hline- & 3.70 & 3.47 & N.A. & $6.6 \%$ \\
6.50 & 6.40 & 6.56 & $0.9 \%$ & $2.4 \%$ \\
7.14 & Not given & 7.31 & $2.3 \%$ & N.A. $^{\mathrm{a}}$ \\
8.22 & Not given & 8.21 & $0.1 \%$ & N.A. \\
\hline
\end{tabular}

${ }^{\mathrm{a}} N . A$. not applicable 
model (flexible response with $\mathrm{T}>0.06 \mathrm{~s}$ ). The above statement indicates that not only the mass of the nonstructural component but also the type of connection rigid/flexible should be given due consideration for the seismic analysis. This conclusion comes in agreement with the research outcome mentioned above (Azizpour and Hosseini 2009) in which the type of connection (e.g. diameter of ring elements) affected the frequency of the system. However, this issue has not received much attention in the literature and additional loading effects should be considered e.g. thermal and pressure. Usually, rigid mechanical supports are considered for the pipes. Also, it is common most of the degrees of freedom of steel supports to be unrestrained in order to avoid excessive sizing of beams cross sections. The analysis of pipes and pipe supports independently of the rack could yield in considerable underestimation of pipes response e.g. displacements.

In the present case study, both the nonbuilding-nonstructural components and supporting structure are modelled and analysed together since $\mathrm{W}_{\mathrm{p}}>25 \%$ and $\mathrm{T}>0.06$ (the analysis for estimating the fundamental frequency of the vessels and piping system includes the towers on which are supported on).

The structural type to be used for modelling pipe racks depends on the single case and should always be compatible with design code provisions; for instance, the use of modular pipe racks is extensive in oil and gas industry due to financial reasons and the type of connections is strongly related with the distribution of pipes and/or vessels weight as well as fabrication cost. Pinned connections are typically utilized for beams in the longitudinal direction (struts) and shear tabs for the transverse (bent) beams. Also, the type and location of bracing is essential for the transportation, lifting and support of permanent and operating loads. As an example, vertical bracing could be used to support side overhang cantilevers that are necessary for pipelines that run out of the main pipe rack frame (Bedair 2015). In the present case-study, the petrochemical steel pipe rack is considered first as an Ordinary Concentrically Braced Frame (OCBF) with horizontal and vertical bracing (more info about this structural type can be found in Imanpour et al. (2011) and is modelled on ABAQUS software. The assumption of the low ductility class (ordinary structure) comes after the low deformation demand for pipe racks. The rack is placed in a high seismic-prone area in the north-eastern part of Sicily (near Milazzo city), in Southern Italy, where an oil refinery is located, and designed according to the Italian NTC (2018) and the two European codes EN 1993-1-1 (2005) and EN1998-1 (2004) for the Safe Life Limit State (SLLS) with recurrence period equal to 712 years (or probability of exceedance $7 \%$ within 50 years as per NTC (2018). The design parameters of the pipe rack can be found in Table 5 .
Table 5 Design parameters for the pipe rack (NTC 2008)

\begin{tabular}{ll}
\hline Location & $\begin{array}{l}\text { Coastal } \\
\text { site near } \\
\text { Milazzo, } \\
\end{array}$ \\
& Sicily \\
\hline Soil & $\mathrm{C}$ \\
q-factor & 2.17 \\
Importance class & III (Essen- \\
& tial facil- \\
PGA & ity) \\
Recurrence period, T & 0.18 \\
\hline
\end{tabular}

The piping system is designed according to the Allowable Stress Method (ASM) as specified in EN13480-3 (2012) and ASME B31.3 (2008) and analysed taking both inertial effects and differential movements of the supports into account (coupled case). It is emphasised that in case of decoupled system, which is out of the scope of this casestudy, only the inertia effects of pipes can be evaluated. Furthermore, the EN13480-3 (2012) code makes reference to two seismic levels, viz Operating Basis Earthquake (OBE) and Safe Shutdown Earthquake (SSE), whereas the latter one only to OBE (or occasional loads as they are defined in the code). It is emphasized that the ASCE/SEI 7-16 (2017) proposes additional seismic acceptance criteria for nonstructural components e.g. allowable peak spectral acceleration at attachment points or relative displacement between attachment points that are not included in EN13480-3 (2012) and ASME B31.3 (2008). The latter codes pertain mainly to the design of pipelines itself without considering dynamic interaction with attachment structures. Following this design methodology, other acceptance criteria could be assessed in order to enhance the design methodology in future publications. Also, it is pointed out that the lower q-factor value between the piping system and the supporting structure is adopted, since the coupled case is considered. This assumption and the reduction factor come after the ASCE/SEI 7-16 (2017) (see also Table 2), considering that EN code still does not specify values of q-factor for pipe racks yet only for irregular structures, which may be unsafe due to the pipe rack-nonstructural components interaction as well as the high risk existing in oil industry.

Finally, a modal analysis has also been conducted and the first two fundamental mode shapes excite the $42 \%$ and $26 \%$ of the total mass of the structure in the $\mathrm{Y}$ - and $\mathrm{X}$-direction (Fig. 4), respectively.

In contrast with the common building structures, the highest modal participating mass ratio is observed at higher modes e.g. 6th mode, and that makes the use of common design and assessment methodologies questionable. Also, 
Fig. 4 The two principal modal shapes: a perspective view, and b plan view

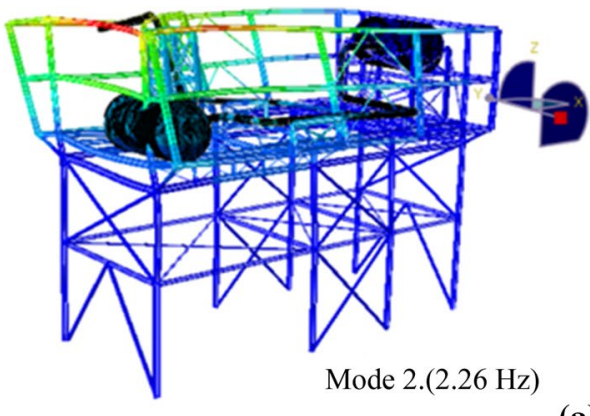

(a)
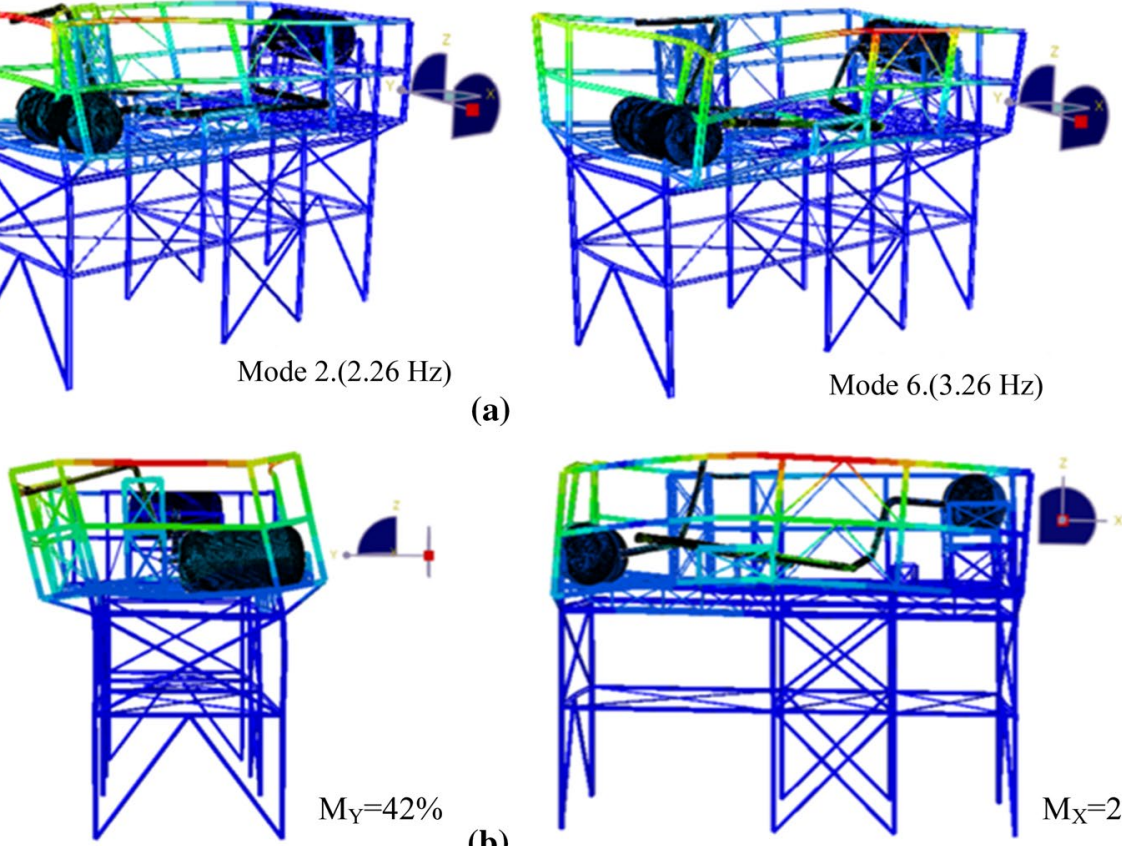

(b)

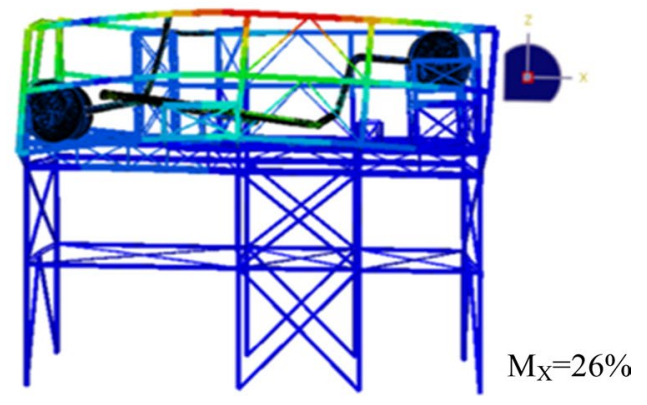

the interaction of nonstructural components and building structure could be affected by higher modes.

\subsection{Seismic Assessment of Steel Rack}

Due to the high irregularity of the pipe rack and high uncertainty of the effects of pipe rack-piping system interaction, the evaluation of system performance factor (q) is considered necessary. In doing so, the reliability of the factor proposed by the codes can be assessed and design parameters that are commonly adopted for common buildings can be highlighted. According to ASCE/SEI 7-16 (2017) and the guideline ASCE (2011), the selection of analysis method depends on design category, structural system, dynamic properties and regularity of the structure. The equivalent later force and dynamic analysis methods are commonly used for petrochemical plant structures. Considering the mass and stiffness irregularities of the rack along the height, the dynamic analysis is arguably the best choice, however,in the framework of this case-study, the conventional PA is used first to estimate the behaviour factor of the pipe rack considering the inertia forces concentrated at each floor (uniform distribution). Furthemore, the Incremental Dynamic Analysis (IDA) follows in order to assess the accuracy of the previous method for pipe racks. Seismic codes encourage both methods to be used for making comparisons e.g. in terms of base shear. Since there is no slab at the third floor to ensure a diphragmatic behaviour (see also Fig. 2a), the response is monitored at different control points along the perimeter of the third floor of the pipe rack to examine possible variation of the seismic behaviour; in the following only the worst case -point with the highest IDR- is presented, though. The substantial reduction of rack lateral resistance considering the force-deformation curve is adopted as global collapse limit state for each direction (Mwafy and Elnashai 2001). Also, the criterion used to define the global yield threshold, which is necessary for the behaviour factor estimation, is selected as the yield displacement at $75 \%$ of the maximum strength of the original force-displacement curve compared to the equivalent elasto-plastic system. The ductility factor is estimated by using the equal displacement method. In more details, the ductility fuctor $\left(\mathrm{r}_{\mu}\right.$, see also Eq. 3 ) was calculated first by deviding the maximum elastic force $\mathrm{F}_{\mathrm{e}}$ with the yeilding one $\left(\mathrm{F}_{\mathrm{y}}=0.75 \cdot \mathrm{F}_{\max }\right)$. Furthermore, the ductility factor was multiplied with the ovestrength $r_{s}\left(=F_{y} / F_{d}\right.$, where $F_{d}$ is the design base shear obtained by the response spectrum analysis) to acquire the non-risk related q-factor. More information about the ductility and behaviour factor estimation can be found in Elnashai and Di Sarno (2015).

The assessment of the rack with the nonlinear time-history analysis is conducted using a suite of 7 seismic records that refer to near-field conditions with epicentral distance smaller than $15 \mathrm{kms}$ (Table 6 and Fig. 5). It is worth mentioning that, although that distance threshold was generally accepted in the past (Chopra and Chintanapakdee 2001; Heydari and Mousavi 2015) for differentiating far-field and near-field records, nowadays, the epicentral distance is not the only parameter to be considered; parameters such as the fault directivity and fling-step are also accounted for. More information can be found among others in Iervolino et al. (2017) and Pacor et al. (2018). To be consistent with the pushover analysis, the same criterion is adopted for defining 
Table 6 The seismic records considered for the IDA

\begin{tabular}{|c|c|c|c|c|c|c|c|c|c|}
\hline \# & Earthquake name & Date & $\mathrm{M}_{\mathrm{W}}$ & $\begin{array}{l}\text { Epicentral } \\
\text { distance } \\
(\mathrm{km})\end{array}$ & $\begin{array}{l}\text { PGA } \\
X(g)\end{array}$ & $\begin{array}{l}\text { PGA } \\
\text { Y (g) }\end{array}$ & $\begin{array}{l}\text { PGA } \\
Z(g)\end{array}$ & $\begin{array}{l}\text { Bracketed } \\
\text { duration }{ }^{a} \\
\text { (s) }\end{array}$ & $\begin{array}{l}\text { Predominant } \\
\text { period }(\mathrm{s})\end{array}$ \\
\hline 1 & Faial & 09/07/1998 & 6.1 & 11.00 & 0.420 & 0.382 & 0.317 & 8.42 & 0.476 \\
\hline 2 & Banja Luka & $13 / 08 / 1981$ & 5.7 & 7.00 & 0.442 & 0.404 & 0.209 & 6.00 & 0.119 \\
\hline 3 & Pyrgos & 26/03/1993 & 7.2 & 1.00 & 0.102 & 0.188 & 0.073 & 5.50 & 0.172 \\
\hline 4 & Dinar & 01/10/1995 & 6.4 & 8.00 & 0.273 & 0.319 & 0.130 & 26.40 & 0.303 \\
\hline 5 & UMarche & 26/09/1997 & 4.3 & 3.00 & 0.345 & 0.261 & 0.373 & 7.62 & 0.179 \\
\hline 6 & Duzce & $12 / 11 / 1999$ & 6.0 & 5.27 & 0.525 & 0.414 & 0.361 & 23.57 & 0.417 \\
\hline 7 & Miyagi & $27 / 07 / 2003$ & 5.8 & 9.93 & 0.199 & 0.257 & 0.259 & 20.00 & 0.132 \\
\hline
\end{tabular}

${ }^{\mathrm{a}}$ The bracketed duration refers to threshold value of $0.03 \mathrm{~g}$

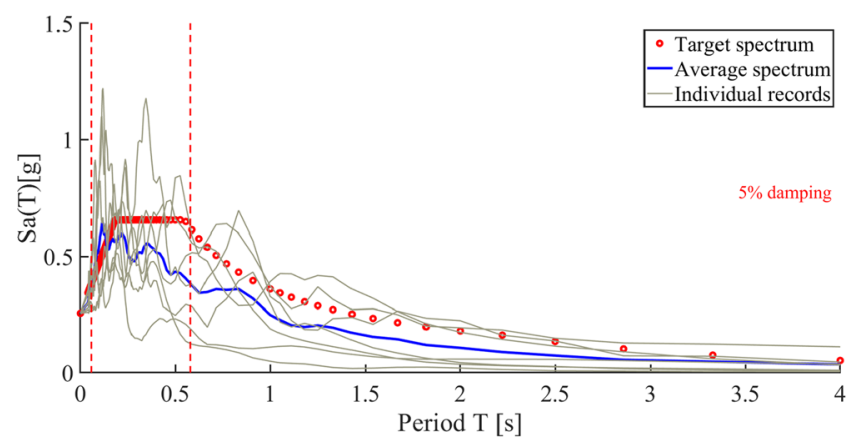

Fig. 5 The response spectra of the records in both directions

global collapse and yielding of the system (Fig. 6). The seismic records are scaled up to collapse based upon the maximum Peak Ground Acceleration (PGA) in the two horizontal directions, however, the vertical component is scaled as well in order to keep the V/H ratio constant (Mwafy and Elnashai 2001).

Comparing the seismic response based upon the two analysis methodologies, it is obvious that the PA overestimates the rack resistance, and thus makes the use of PA analysis questionable. The overestimation seems to be considerably high in the $\mathrm{Y}$ direction since for IDR $=0.8 \%$, when the maximum resistance is achieved according to PA, the pertinent value for IDA is 1.86 times lower. Also, the pipe rack is considerably more ductile in the Y-than in the X-direction since the ductility factor occurred $45 \%$ higher in the former direction, and this might be due to the tank response considering that there is no slab in order to support the weight in a utterly uniform manner and the longitudinal direction of it runs in the Y-direction making the tank to be more rigidly restrained in the other direction. Most probably, this is the reason why the PA method overestimates the behaviour factor as shown in Table 7, since the last method is not capable of activating the tank mass and cause torsional effects in the entire system. What is also of interest pertains to the outcome of the factor in the $\mathrm{Y}$ direction when comparing the
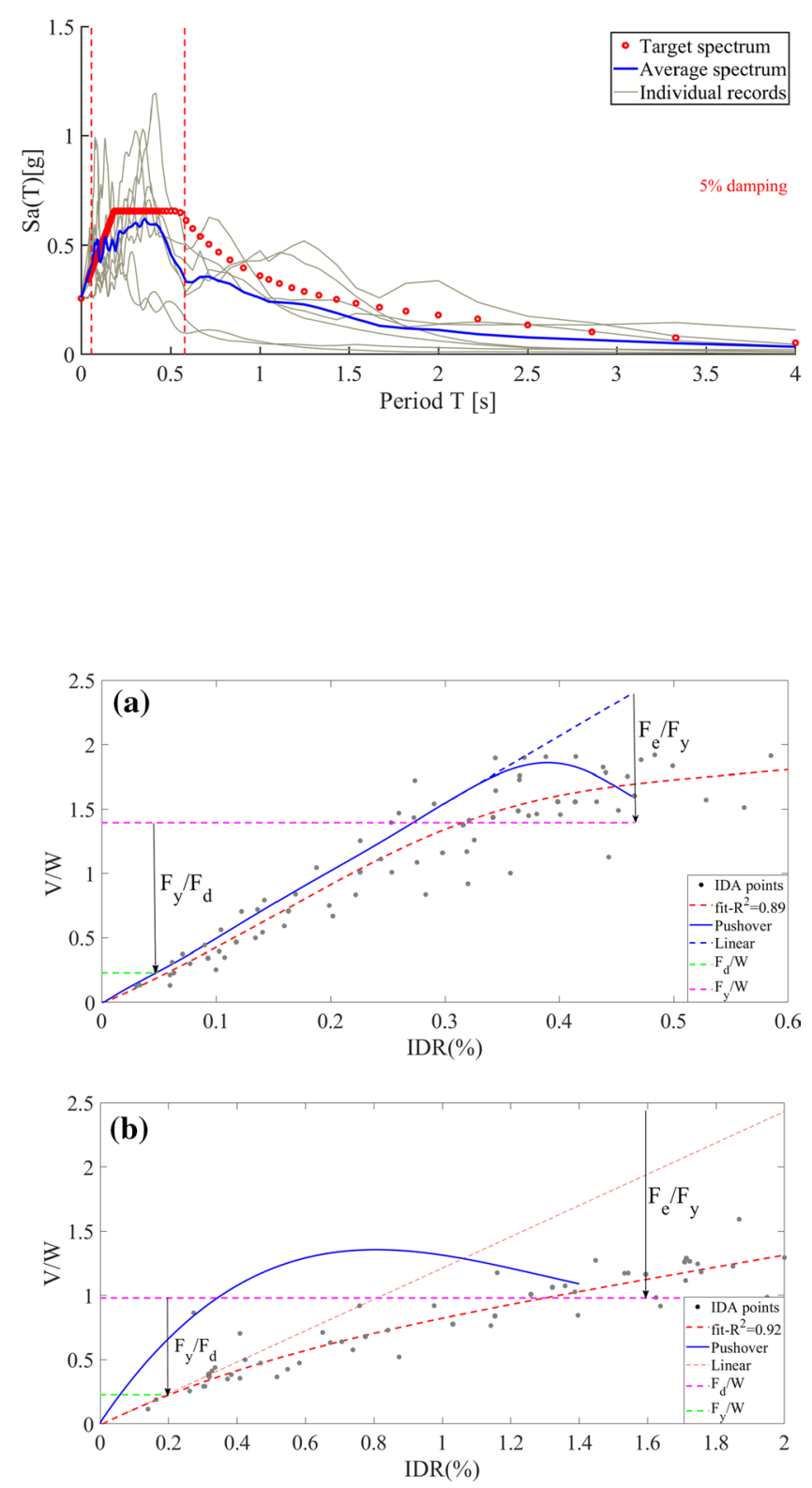

Fig. 6 The capacity curves for the two directions and two analyses methods, namely pushover and time-history or IDA 
Table 7 Behaviour factors for the pipe rack

\begin{tabular}{llclll}
\hline & \multicolumn{2}{l}{ Ductility factor } & & \multicolumn{2}{l}{ Behaviour factor } \\
\cline { 2 - 3 } \cline { 5 - 6 } & X-direction & Y-direction & & X-direction & Y-direction \\
\hline Pushover & 1.70 & 3.76 & & $10.6(1.82)$ & $15.2(2.61)$ \\
IDA & 1.85 & 2.68 & & $9.04(1.55)$ & $14.7(2.53)$ \\
$\%$ & +8.9 & -28.7 & & -14.7 & -3.3 \\
\hline
\end{tabular}

two methodologies; the value yielded by the PA is almost $29 \%$ higher than IDA.

Furthermore, the risk-targeted behaviour factor is estimated for mean annual frequency of collase $\left(\lambda_{\text {CLS }}\right)$ equal to $2 \times 10^{-4}$ that corresponds to a generally accepted value that has been adopted in the development of building codes. As it was expected, the product of ductility and overstrength factor is extremely high. When the results of IDA are considered, the factor fluctuates from 9 to roughly 15 in both directions. To estimate the factor accounting for the designated risk, the risk-equation is used. To this effect, the annual rate of exceedance $\left(\lambda_{\mathrm{IM}}\right)$ of seismic intensity at the site under consideration is evaluated using the REASSES software (Chioccarelli et al. 2018). By assuming that the standard deviation of the fragility function is equal to $\beta=0.4$, which is a generally accepted value in the literature for code-conforming buildings (Dolšek et al. 2017a, b), and changing repetitively the median of IM that causes 50\% probability of collapse, the fragility and hazard curves are convoluted till achieving the desirable mean annual frequency of collapse $\left(\lambda_{\text {CLS }}\right)$. A snapshot from the iterative process is given below (Fig. 7). Also, the results of the factor that account for the target-risk are quoted in Table 7 in parentheses. Considering only the values of factor by IDA, the factor was $29 \%$ less than the design value in the $\mathrm{X}$-direction and $16 \%$ higher in the other direction. The inconsistency of the factor with the design value may indicates that the factors proposed by the code might not be always on the safe side and surely unjustifiable.

Having examined the response of the rack in terms of IDR, it is essential the stress/strain distribution on pipes (local scale) to be checked as well in order to adjudicate the reliability of the design method and compare the pipes response with the IDR values, which were found previously, as well as the maximum Peak Floor Acceleration (PFA) as defined by ASCE/SEI 7-16 (2017). For that purpose, the two seismic levels, OBE and SSE, are considered. The maximum floor acceleration is recorded at multiple points of the third floor of the rack yet only the maximum PFA is considered herein. According to ASCE/SEI 7-16 (2017), the PFA shall not exceed three times the PGA of seismic input $\left(\mathrm{S}_{\mathrm{e}(\mathrm{T}=0)}=0.26 \mathrm{~g}\right)$. The first comment on the results shown in Fig. 8 refers to the fact that the piping system stress remains below the yielding value for both seismic levels. It is worth noting that the rack has considerably high overstrength and low ductility, which makes the common IDR values not applicable for the present rack. Additionally, the PFA presents high dispersity among the seven 7 records

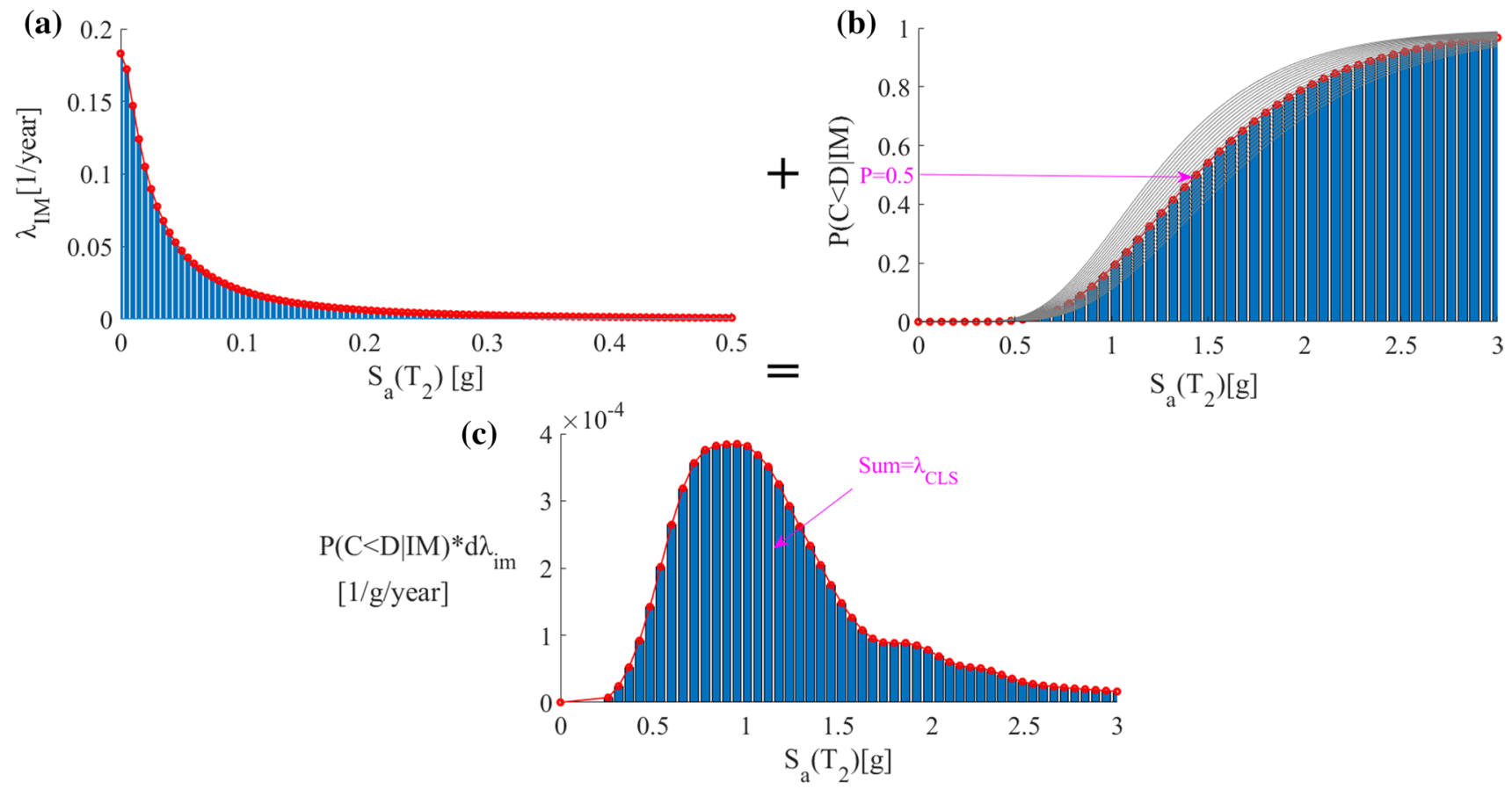

Fig. 7 The convolution of a hazard curve with $\mathbf{b}$ fragility curve towards obtaining $\mathbf{c}$ the requested mean annual frequency of exceedance of CLS $\left(\lambda_{\text {CLS }}\right)$ 

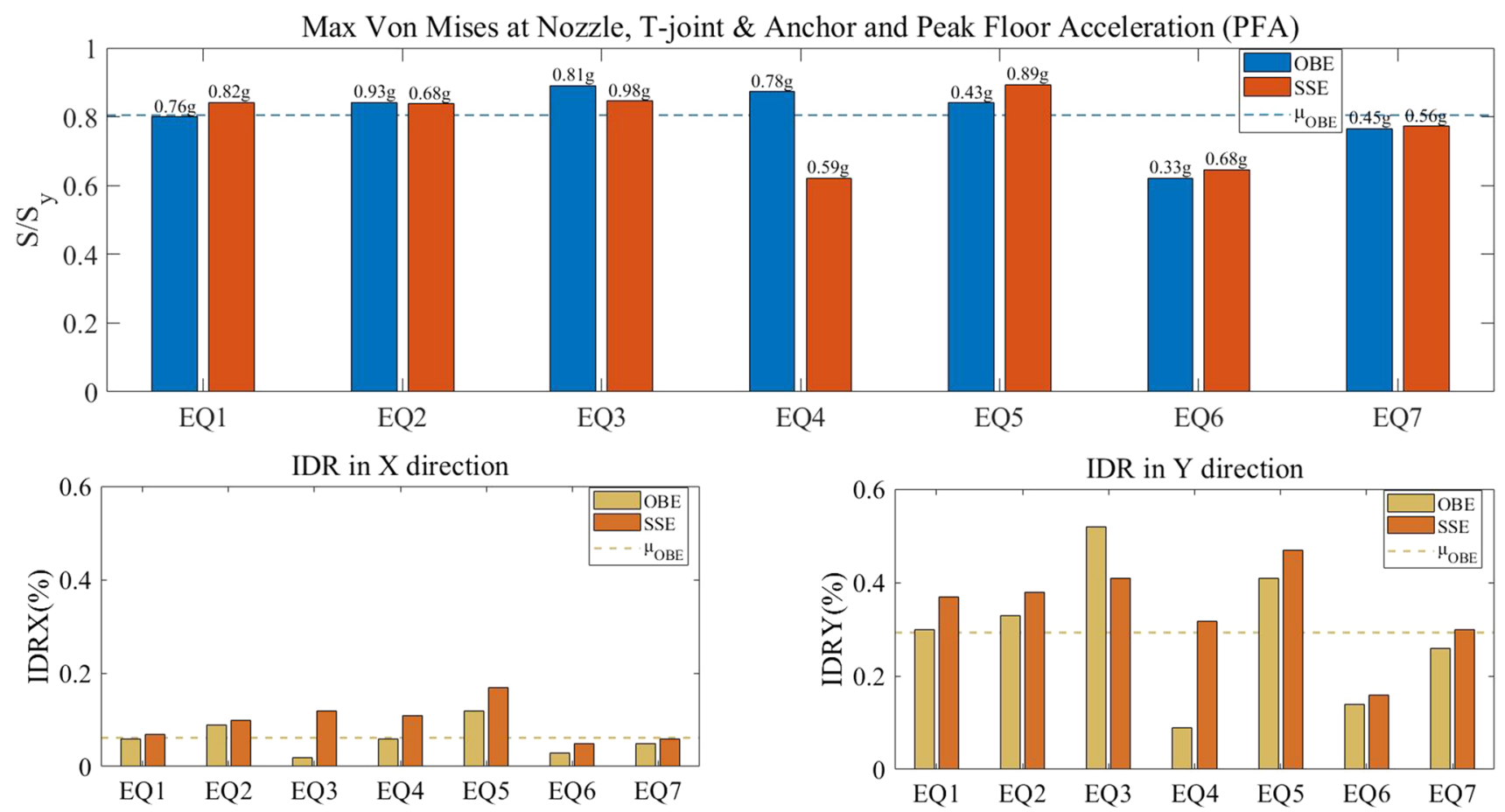

Fig. 8 The coupling response of nonbuilding-nonstructural components in terms of pipe stress, PFA and IDR considering for two seismic levels

being even greater than the allowable value proposed by the code $\left(3 \cdot \mathrm{S}_{\mathrm{e}(\mathrm{T}=0)}\right)$ and this is an indication that the code ASD method could be unsafe. Usually, the variability around the mean value is expressed in terms of Coefficient of Variation (CV). Regarding the OBE, the CV is equal to $11 \%$ for the stress distribution, between 50 and $60 \%$ for the IDR in both directions and $36 \%$ in case of PFA. The high values of $\mathrm{CV}$, particularly in the last two cases, may signify the complexity of pipe rack-piping system interaction.

To examine further the variation and amplification of PFA, the pipe rack is also analysed in the linear regime. Comparing the Fig. 9a, b, it is obvious that the linear behaviour increases considerably the PFA leading to values greaten than 1.5 times the limit value proposed by ASCE
7-16. This behaviour has also been observed in other steel frame buildings (e.g. Flores et al. 2015). This outcome may signify that the attitude of industrial engineers to analyse pipe racks in the linear range for safety reasons could be detrimental for the seismic safety of nonstructural components.

A common analysis method for nonstructural components pertains to 'floor response spectra' where spectra are collected by computing the total acceleration response history at the floor of interest. The spectra for linear and nonlinear material are presented in Fig. 10a, b and regard the median value of response time histories recorded on the third floor. The flexible pipelines should comply with the acceleration demand $\left(0.4 \cdot a_{p} \cdot S_{D S} \cdot(1+2 z / h)\right.$, where $a_{p}$ is an amplification factor equal to 2.5 for flexible components and
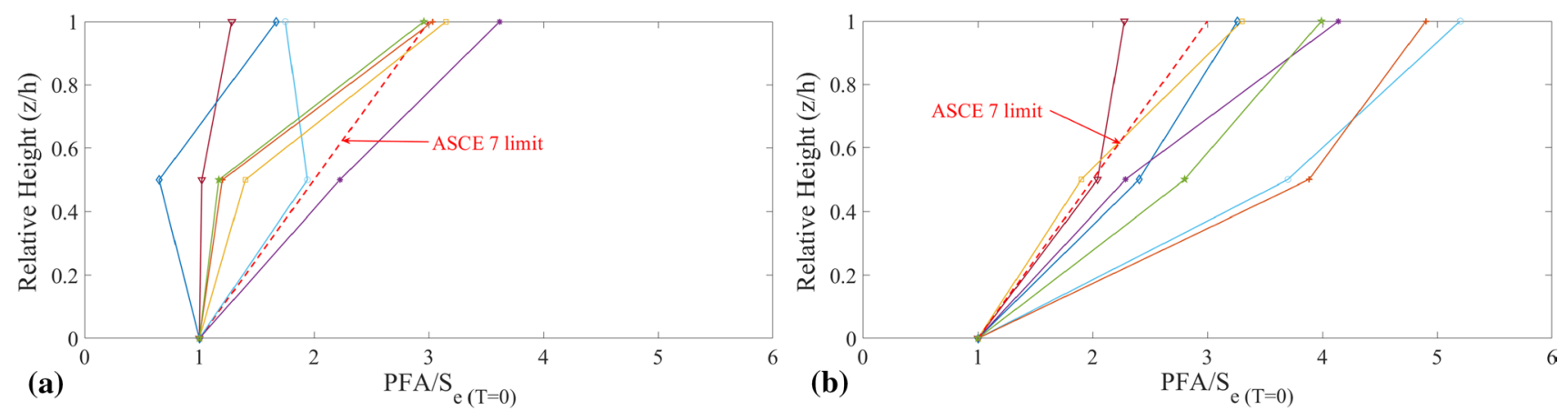

Fig. 9 The variation of PFA for the 7 records along the pipe rack height for a nonlinear and $\mathbf{b}$ linear behaviour 


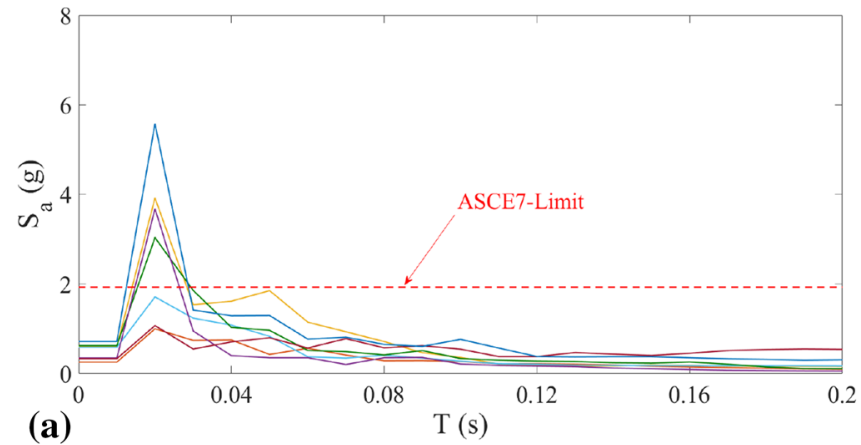

(a) $\mathrm{T}(\mathrm{s})$

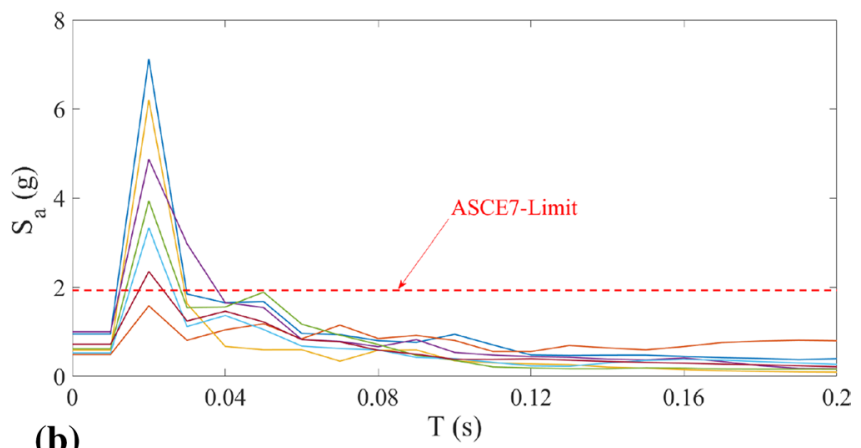

(b)

Fig. 10 The response spectra for the 7 records on the third floor for $\mathbf{a}$ nonlinear and $\mathbf{b}$ linear behaviour

$\mathrm{S}_{\mathrm{DS}}$ is the design spectral acceleration) implicitly indicated in the formula for the horizontal seismic design force $\left(\mathrm{F}_{\mathrm{p}}\right)$ for nonstructural components in ASCE 7-16. The maximum spectrum acceleration observed 3.7 and 2.9 times the acceleration demand in the two cases, and obviously, protective measures are required for the seismic safety of piping system such as supporting the tanks more rigidly on the rack and/ or bracing, beams and columns reconfiguration. This issue is being investigated by the Authors.

\section{Conclusions}

The research above showed several dissimilarities that characterise the non-building structures compared to common ones. The behaviour factor is defined with different reliability target in the European (EC8-1) and American (ASCE 7) standards as well as the former code do not deal with non-building structures. Also, the importance factor presents dissimilarities among the codes, which are illustrated when comparing the maximum spectral acceleration of response spectra. The aforementioned factors have not rigorously been addressed in EC8-1 by taking into account the idiosyncrasy of steel industrial pipe racks such as the interaction between structural and nonstructural components due to severe earthquake events. A steel pipe rack was investigated as the first case-study and the main outcomes are the following:

- The PA analysis found incapable of estimating the lateral resistance of the pipe rack since the capacity curve from PA was lower than that of IDA method in both directions.

- The behaviour factor was overestimated up to $30 \%$ by PA. Also, the factor was found even less than the proposed value by the code and thus any consideration of code values could be unjustifiable and unsafe.

- Common IDR values, particularly in the X-direction, cannot apply for the pipe rack since they do not exceed the value of $0.2 \%$ for the OBE and SSE when the maximum pipe stress is close to $80 \%$ of the yielding point.
- Although the piping system remained in the elastic range as proposed by the ASM, the analysis yielded CV higher than $30 \%$ and $50 \%$ in case of PFA and IDR.

- The PFA acceleration occurred greater than the threshold value prescribed in ASCE 7-16, particularly in the linear regime.

Overall, the research above showed that the design of pipe racks is not straightforward, and thus due consideration should be given e.g. in the behaviour factor selection and analysis methodology. Arguably, the dynamic analysis could be considered the best choice in case of irregular pipe racks of which the response is governed by nonstructural components and other nonbuilding structures. Also, the interaction between the rack and the piping system is a key parameter in the precise and safe design of pipe racks and thus a sensitivity analysis should be used to evaluate the degree of interaction e.g. by investigating the decoupled systems and the additional load in the coupled case by considering thermal and pressure effects. Finally, the soil deformability is another critical design challenge, particularly, when the soil is alluvial and the investigation of soil effects in terms of pipes fragility will give a better insight on the seismic vulnerability of pipe racks.

Acknowledgements The work presented herein has received funding from the European Union's Horizon 2020 research and innovation programme under the Marie Sklodowska-Curie Grant Agreement No 721816. This support is gratefully acknowledged.

Open Access This article is distributed under the terms of the Creative Commons Attribution 4.0 International License (http://creativeco mmons.org/licenses/by/4.0/), which permits unrestricted use, distribution, and reproduction in any medium, provided you give appropriate credit to the original author(s) and the source, provide a link to the Creative Commons license, and indicate if changes were made. 


\section{References}

ABAQUS. (2017). ABAQUS 6.17 analysis user's manual'. Online Documentation Help: Dassault Systèmes.

ANSI-RMI. (2008). Specification for the design, testing and utilization of industrial steel storage racks-MH16.1: 2008.

ASCE. (2011). Guidelines for seismic evaluation and design of petrochemical facilities (2nd ed.). Reston, VA: American Society of Civil Engineers.

ASCE/SEI 7-16. (2017). Minimum design loads and associated criteria for buildings and other structures. https://doi.org/10.1061/97807 84414248

Asgarian, B., Sadrinezhad, A., \& Alanjari, P. (2010). Seismic performance evaluation of steel moment resisting frames through incremental dynamic analysis. Journal of Constructional Steel Research, 66(2), 178-190. https://doi.org/10.1016/j. jcsr.2009.09.001.

Asgarian, B., \& Shokrgozar, H. R. (2009). BRBF response modification factor. Journal of Constructional Steel Research, 65(2), 290-298. https://doi.org/10.1016/j.jcsr.2008.08.002.

ASME B31.3. (2008). ASME Code for Pressure Piping, B31-ASME B31.3-2008 (Revision of ASME B31.3-2006). Chemical Engineer, 76(8), 95-108.

Azizpour, O., \& Hosseini, M. (2009). A verification study of ASCE recommended guidelines for seismic evaluation and design of combination structures in petrochemical facilities. Journal of Applied Sciences, 9(20), 3609-3628. https://doi.org/10.3923/ jas.2009.3609.3628

Bedair, O. (2015). Rational design of pipe racks used for oil sands and petrochemical facilities. Practice Periodical on Structural Design and Construction. https://doi.org/10.1061/(ASCE)SC.19435576.0000224.

Bursi, O. S., Paolacci, F., Reza, M. S., Alessandri, S., \& Tondini, N. (2016). Seismic assessment of petrochemical piping systems using a performance-based approach. Journal of Pressure Vessel Technology, Transactions of the ASME. https://doi. org/10.1115/1.4032111

Bursi, O. S., Reza, M. S., Abbiati, G., \& Paolacci, F. (2015). Performance-based earthquake evaluation of a full-scale petrochemical piping system. Journal of Loss Prevention in the Process Industries, 33, 10-22. https://doi.org/10.1016/j.jlp.2014.11.004.

Celano, F., Žizmond, J., \& Dolsek, M. (2018). The evalutation of risktargeted safety factor and behaviour factor for selected steel structures. In 16th European conference on earthquake engineering. Thessaloniki.

Chioccarelli, E., Cito, P., Iervolino, I., \& Giorgio, M. (2018). REASSESS V2.0: Software for single- and multi-site probabilistic seismic hazard analysis. Bulletin of Earthquake Engineering (submitted). https://doi.org/10.1007/s10518-018-00531-x

Chopra, A. K., \& Chintanapakdee, C. (2001). Comparing response of SDF systems to near-fault and far-fault earthquake motions in the context of spectral regions. Earthquake Engineering and Structural Dynamics. https://doi.org/10.1002/eqe.92.

DeGrassi, G., Nie, J., \& Hofmayer, C. (2008). Seismic analysis of large-scale piping systems for the JNES-NUPEC ultimate strength piping test program. Retrieved from http://scholar.googl e.com/scholar?hl=en\&btnG=Search\&q=intitle:Seismic + Analy sis+of+Large-Scale+Piping+Systems+for+the+Ultimate+Stren gth+Piping+Test+Program\#1. Accessed 5 Dec 2018.

Di Roseto, A. A. D. L., Palmeri, A., \& Gibb, A. G. A. G. (2017). Performance-based seismic design of a modular pipe-rack. Procedia Engineering, 199, 3564-3569. https://doi.org/10.1016/j.proen g.2017.09.519.

Dolšek, M., Kosič, M., Žižmond, J., \& Lazar Sinković, N. (2017a). Development of Eurocode 8, Proposal for Annex F (Informative)
Simplifed reliability-based verification format, Rev. 3, University of Ljubljana, 16.6.2017, Ljubljana.

Dolšek, M., Lazar Sinković, N., \& Žižmond, J. (2017b). IM-based and EDP-based decision models for the verification of the seismic collapse safety of buildings. Earthquake Engineering and Structural Dynamics, 46(15), 2665-2682. https://doi.org/10.1002/eqe.2923.

Drake, R. M., \& Walter, R. J. (2010). Design of structural steel pipe racks. AISC Engineering Journal, 47, 241-252.

Elghazouli, A. Y. (2009). Assessment of European seismic design procedures for steel framed structures. Bulletin of Earthquake Engineering, 8(1), 65-89. https://doi.org/10.1007/s1051 8-009-9125-6.

Elnashai, A. S., \& Di Sarno, L. (2015). Fundamentals of earthquake engineering: From source to fragility (2nd ed.). New York: Wiley. https://doi.org/10.1002/9780470024867.fmatter/pdf.

EN 1993-1-1. (2005). Eurocode 3: Design of steel structuresPart 1-1: General rules and rules for buildings. Eurocode 3, 1(2005), 91 pp. [Authority: The European Union Per Regulation 305/2011, Directive 98/34/EC, Directive 2004/18/EC].

EN13480-3. (2012). EN 13480-3, 2002, Metallic Industrial PipingPart 3: Design and Calculation. Brussels: CEN.

EN1998-1. (2004). Eurocode 8: Design of structures for earthquake resistance-Part 1: General rules, seismic actions and rules for buildings. European Committee for Standardization (Vol. 1). [Authority: The European Union per Regulation 305/2011, Directive 98/34/EC, Directive 2004/18/EC].

EN1998-6. EN 1998-6. (2005). (English): Design of structures for earthquake resistance-Part 6: Towers, masts and chimneys [Authority: The European Union Per Regulation 305/2011, Directive 98/34/EC, Directive 2004/18/EC] (2005).

FEM10.2.08. (2011). Recommendations for the design of static steel pallet racks in seismic conditions-Version 1.04, Pub. L. No. Version 1.04.

FEMA P-751. (2012). NEHRP recommended provisions: Design examples. https://doi.org/10.1017/CBO9781107415324.004

Flores, F. X., Lopez-Garcia, D., \& Charney, F. A. (2015). Assessment of floor accelerations in special steel moment frames. Journal of Constructional Steel Research. https://doi.org/10.1016/j. jesr.2014.12.006

Heydari, M., \& Mousavi, M. (2015). The comparison of seismic effects of near-field and far-field earthquakes on relative displacement of seven-storey concrete building with shear wall. Current World Environment, 1, 1. https://doi.org/10.12944/ cwe.10.special-issue1.07.

IBC. (2015) International Code Council. Building Officials and Code Administrators International. International Conference of Building Officials. Southern Building Code Congress International.

Iervolino, I., Baltzopoulos, G., Chioccarelli, E., \& Suzuki, A. (2017). Seismic actions on structures in the near-source region of the 2016 central Italy sequence. Bulletin of Earthquake Engineering. https://doi.org/10.1007/s10518-017-0295-3.

Imanpour, A., Tremblay, R., \& Davaran, A. (2011). Seismic performance of steel concentrically braced frames with bracing members intersecting columns between floors. In Behaviour of steel structures in seismic areas, (February 2015) (pp. 447-453). https://doi.org/10.1201/b11396-69

Izadinia, M., Rahgozar, M. A., \& Mohammadrezaei, O. (2012). Response modification factor for steel moment-resisting frames by different pushover analysis methods. Journal of Constructional Steel Research, 79, 83-90. https://doi.org/10.1016/j. jcsr.2012.07.010.

Karamanos, S. A., Patkas, L. A., \& Platyrrachos, M. A. (2006). Sloshing effects on the seismic design of horizontal-cylindrical and spherical industrial vessels. Journal of Pressure Vessel Technology, 128(3), 328. https://doi.org/10.1115/1.2217965. 
Kidam, K., \& Hurme, M. (2013). Analysis of equipment failures as contributors to chemical process accidents. Process Safety and Environmental Protection, 91(1-2), 61-78. https://doi. org/10.1016/j.psep.2012.02.001.

Krausmann, E., Cruz, A. M., \& Affeltranger, B. (2010). The impact of the 12 May 2008 Wenchuan earthquake on industrial facilities. Journal of Loss Prevention in the Process Industries, 23(2), 242-248. https://doi.org/10.1016/j.jlp.2009.10.004.

Krausmann, E., Renni, E., Campedel, M., \& Cozzani, V. (2011). Industrial accidents triggered by earthquakes, floods and lightning: Lessons learned from a database analysis. Natural Hazards, 59(1), 285-300. https://doi.org/10.1007/s1106 9-011-9754-3.

Miranda, E., \& Bertero, V. V. (1994). Evaluation of strength reduction factors for earthquake-resistant design. Earthquake Spectra, 10(2), 357-379. https://doi.org/10.1193/1.1585778.

Mwafy, A. M., \& Elnashai, A. S. (2001). Static pushover versus dynamic collapse analysis of RC buildings. Engineering Structures. https://doi.org/10.1016/S0141-0296(00)00068-7.
NTC. (2018). "Norme Tecniche per le costruzioni”, DM Infrastructure, 14 January (2008) (in Italian).

Pacor, F., Felicetta, C., Lanzano, G., Sgobba, S., Puglia, R., D’Amico, M., et al. (2018). NESS1: A worldwide collection of strong-motion data to investigate near-source effects. Seismological Research Letters, 89(6), 2299-2313. https://doi.org/10.1785/0220180149.

Sezen, H., Asce, M., \& Whittaker, A. S. (2006). Seismic performance of industrial facilities affected by the 1999 Turkey earthquake, (February) (pp. 28-36).

Suzuki, K. (2008). Earthquake damage to industrial facilities and development of seismic and vibration control technology. Journal of System Design and Dynamics, 2(1), 2-11. https://doi.org/10.1299/ jsdd.2.2.

Publisher's Note Springer Nature remains neutral with regard to jurisdictional claims in published maps and institutional affiliations. 